\title{
Did carbon emission trading system reduce emissions in China? An integrated approach to support policy modeling and implementation
}

\author{
Lin Aihua ${ }^{1} \cdot$ Pier Paolo Miglietta ${ }^{2} \cdot$ Pierluigi Toma $^{3}$
}

Received: 13 October 2020 / Accepted: 13 April 2021 / Published online: 6 May 2021

(c) The Author(s) 2021, Corrected Publication 2021

\begin{abstract}
As the highest carbon emission country in the world, it is particularly important to investigate the implementation effect of China's carbon emission trading (CET) system. Because of the complexity to figure out the counterfactual effect when a single unit is treated, the counterfactual and causal effects of the CET system on the carbon emissions are seldom identified. In order to overcome the weakness that counterfactual effect is difficult to be verified and policy persistence is difficult to be estimated, Synthetic Control Method (SCM) and Regression Discontinuity (RD) are combined to better understand and evaluate the impact of CET system in China. Through the analysis, it is found that CET system is effective in China, but the effect is driven by economic development, energy consumption, FDI and other variables. Because of the differences in economic, geographical, technological and environmental conditions in various areas, each Chinese provincial government should formulate a targeted policy according to local conditions, ensuring an economic and environmentally sustainable growth in the future.
\end{abstract}

Keywords Carbon emission trading system - Synthetic control method $\cdot$ Regression discontinuity $\cdot$ Policy implementation assessment $\cdot$ China

JEL Classification Q5 - O1 · F6 · E6

Pierluigi Toma

pierluigi.toma@unisalento.it

Lin Aihua

$569138541 @ q q . c o m$

1 College of Business, Minnan Normal University, Zhangzhou, Fujian, China

2 Dipartimento di Scienze e Tecnologie Biologiche ed Ambientali, University of Salento, Via per Monteroni, 73100 Lecce, Italy

3 Dipartimento di Scienze dell'Economia, University of Salento, Via per Monteroni, 73100 Lecce, Italy 


\section{Abbreviations}

$\begin{array}{ll}\text { CET } & \text { Carbon emission trading } \\ \text { CGE } & \text { Computable general equilibrium; } \\ \text { DID } & \text { Difference-in-differences } \\ \text { EKC } & \text { Environmental Kuznets curve } \\ \text { GHG } & \text { Greenhouse gases } \\ \text { IPAT } & \text { Impact is function of population, affluence, technology } \\ \text { IPCC } & \text { Intergovernmental panel on climate change } \\ \text { MAC } & \text { Marginal abatement cost } \\ \text { RD } & \text { Regression discontinuity } \\ \text { RMSPE } & \text { Root mean square prediction error (RMSPE) } \\ \text { RMSE } & \text { Root means square error } \\ \text { SCM } & \text { Synthetic control method } \\ \text { STIRPAT } & \text { Stochastic impacts by regression on population, affluence and } \\ & \text { technology }\end{array}$

\section{Introduction}

Carbon emissions represent an important issue for human beings in the twenty-first century and it is one of the major obstacles for achieving good environmental performances [14].

As the world's largest carbon dioxide emission country, the implementation of China's carbon emission trading system has attracted world-wide attention. How to reduce carbon emissions is also an important guarantee for China to achieve the goal of sustainable development.

With the Kyoto Protocol's taking into effect as the starting point, the European Union and the United States and other major countries in the world have established carbon emission trading (CET) system. This system is a market mechanism to promote the trading of global greenhouse gas (GHG) emissions mitigation and reduce the global carbon dioxide emissions [28]. In this market mechanism, one party pays the other to obtain permits for carbon emissions. The buyer use purchased emission credits to emit carbon dioxide. Parties covered by CET must have enough emission permits for the amount of the carbon emissions they produce thus CET system can reduce the global carbon emissions volume.

The arrival of carbon emission trading system in China marked a watershed in the history of Chinese climate policy $[11,28]$. The use of market-based CET system is a rather novel attempt in China [46, 47], Jiang and Ma 2014). Chinese government proposed to set up a carbon exchange system for the first time in 2008. And two years later, CET system was put forward by the Chinese State Council. In 2011, the Chinese National Development and Reform Commission issued "notice on the pilot work on carbon emission trading" which approved six provinces and municipalities including Beijing, Shanghai, Tianjin, Chongqing, Hubei and Guangdong to carry out the pilot work of establishing CET system.

However, the implementation of CET system in China is far from mature and might result in poor performance. It is still in the experimental stage and there 
are lots of problems [52], such as low market participation [28], defective of government supervision [53] and lack of incentive mechanism [21]. New research is needed to better understand and evaluate the effect of CET system in China. In line with recent literature which provided a comprehensive overview of current status of China's seven CET system pilots [48], the purpose of this paper is to build an empirical basis to evaluate whether the CET system reduces carbon emissions in Chinese six provinces and municipalities or not. Through comparison and analysis for six provinces and municipalities, the detail effect of CET system in China is presented and ways to reduce carbon emissions are suggested.

\section{Background and study framework}

Scholars' first attention to carbon emission rights can be traced back to 1960s. Based on the application of Coase Theorem I, Crocker [12] affirmed that property right has a positive effect on the target of greenhouse gas emission reduction. Burniaux et al. [7] found that the promotion of CET market can reduce the total carbon emissions of the world. In 1999, Garbaccio et al. used Computable General Equilibrium (CGE) models to study carbon emission reduction measures in developing countries and draw the same conclusion that carbon emission trading system made carbon emissions decrease significantly. Some scholars discussed the CET system in China. Hübler [22], Weitzel et al. [43] believed that the implementation of CET system will bring positive effect to China. Zhou and Chen [53], Lo [29] and Liu et al. (2014) argued that there would be tremendous challenges for CET system in China due to kinds of reasons such as market segmentation, low participation and the defective of pricing mechanism and so on. With the continuous development and application of empirical tools, more models are applied to the study of carbon emissions. Zhou et al. [54] and Cui et al. [13] have constructed an interprovincial carbon emissions trading model to evaluate economic performance and the cost-saving effects of CET system in China. Böhringer et al. [6] used a marginal abatement cost (MAC) curve to specifically simulate the carbon emissions in China and proved that the substantial revenues from permit exports would finally turn the carbon abatement costs into net gains. In 2016, Yi et al. employed a dynamic CGE model to simulate the situation that China had implemented carbon emission trading throughout the whole nation, and revealed that under the double restrictions of economic growth and environmental protection, the interprovincial transaction of carbon emission trading reduced the total amount of carbon emissions. But Zhang's study is based on virtual assumptions, and this paper is now trying to test the effects of existing carbon emission trading system, based on facts instead of virtual assumptions.

In order to study the effect of carbon emission trading system in various provinces and municipalities in China, this paper adopted the synthetic control method (SCM). Compared with other research methods such as difference-indifferences (DID) analysis in panel data, the SCM can overcome the difference between the treatment group and the control group, making the research result more scientific and accurate. SCM is mainly used in comparison cases, and it has been proposed by Abadie and Gardeazaba (2003), who studied the economic 
impact of terrorist attacks in Basque area, Spain. Then Abadie et al. [2] developed and expanded it, studying the effect of tobacco control legislation in California on reducing tobacco consumption per capita.

Abadie et al. [3] used SCM to study the influence of the unification of East and West Germany on the German economy. There were other scholars who used SCM. Zhang et al. [49] used SCM to estimate the impact of the Beijing 2008 Olympic Games on Beijing's air quality, while Castillo et al. [40] used SCM to study the causal effects of regional industrial policies on employment. Samartsidis et al. [34] studies the performance of the canonical synthetic control estimator and of related methods in the context of the German reunification.

Probably because of their interpretability and transparent nature, synthetic controls have become widely applied in empirical research in economics and the social sciences.

Probably because of their interpretability and transparent nature, the SCM literature is vast in its totality and includes many recent noteworthy contributions, widely applied in empirical research in economics and the social sciences [8], $19,44,5,41,10$.

The other method used in this study, i.e. regression discontinuity, was firstly applied in the late $90 \mathrm{~s}$ to deal with economics. As a quasi-random experimental method, regression discontinuity has an incomparable advantage in the empirical causal analysis. Hahn et al. [20] strictly proved the identification and treatment effects for regression discontinuity and Lee [26] argued that regression discontinuity can avoid the endogeneity of variables in random experiments. In the present study regression discontinuity is used to estimate the causal effect of carbon emission trading system and infer the persistence of the effect through a causality analysis, allowing the suggestions of some countermeasures aimed at reducing carbon emissions.

Compared with previous studies, this research provides an innovative framework on how to conduct policy assessment and modeling. The new contributions can be summarized as follows: through Synthetic Control Method (SCM), it is verified whether carbon emission trading system is effective or not and whether there is a discontinuity caused by the CET system or not; using Regression Discontinuity (RD) the causal effect of carbon emission trading system is properly analyzed and the persistence effect of carbon emission trading system based on the result of causal analysis is deduced. Compared with other research methods, the SCM is more scientific from the perspective of counterfactual perspective, but it cannot figure out the sustainability of the policy implementation. Furthermore, RD can show a causal effect after policy implementation, but it cannot identify the specific factors which actually cause the discontinuity.

This study, by adopting an approach which integrates the use of synthetic control method and regression discontinuity, overcomes the defects and provides a new methodological framework for the assessment of policy implementation effect and sustainability, as illustrated in Fig. 1. 


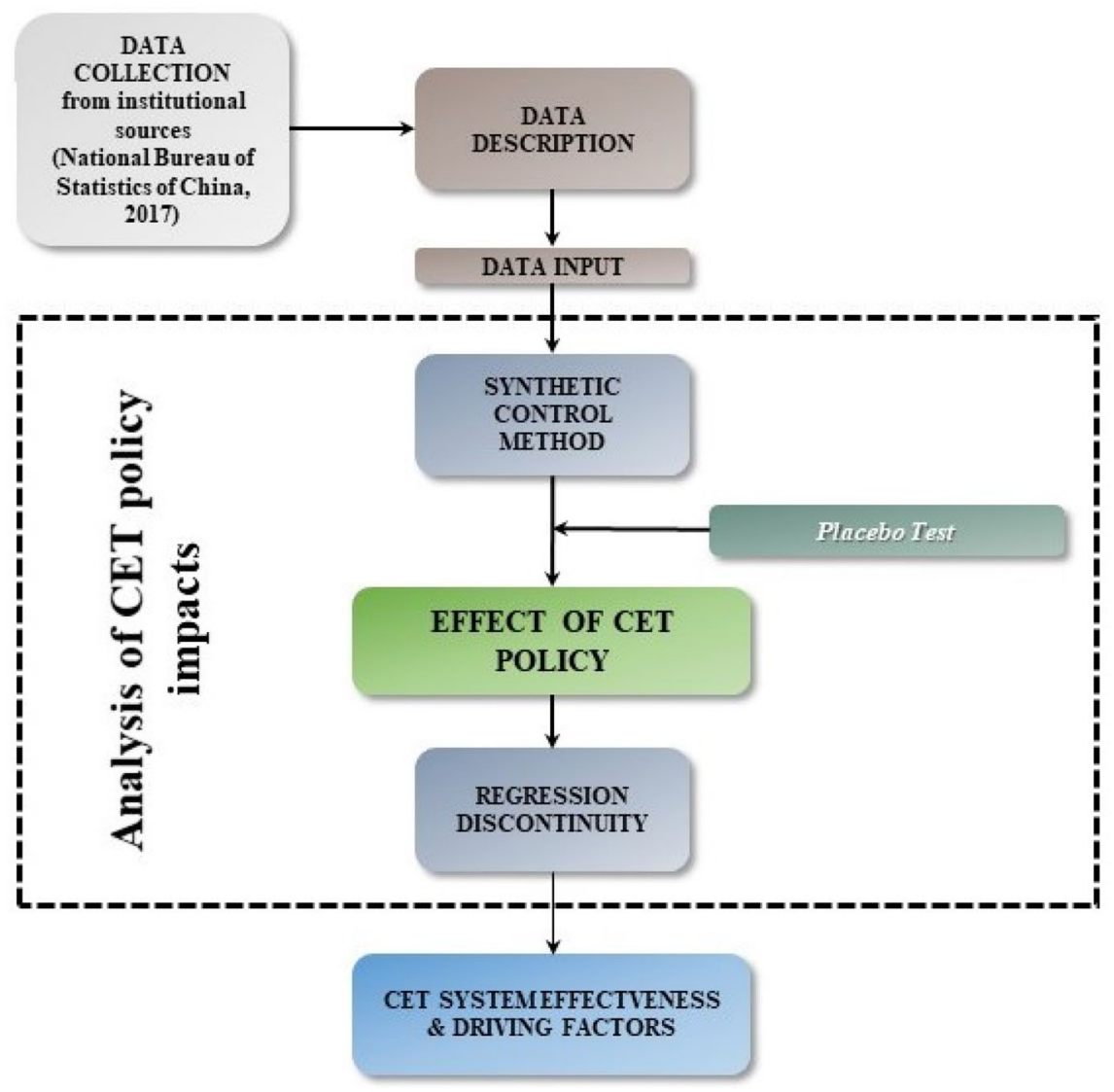

Fig. 1 Methodological framework and data processing fluxes

\section{Data collection}

At present, the series model based on the IPAT model and the series model based on the Kaya identity are two common models used to analyze the influence factors of carbon emissions in the academic fields. The IPAT model proposed by Ehrlich and Holden [15], divides the factors affecting the environmental pressure into three categories: population, affluence and technology. The Kaya identity instead identifies four categories of environmental pressure influencing factors: energy carbon intensity, energy intensity, GDP per capita and total population [24]. Later, the two models were expanded, and new models such as STIRPAT (Stochastic Impacts by Regression on Population, Affluence and Technology) were developed. Although the models are different, the factors which influence carbon emissions are generally recognized. This paper still uses the practices of predecessors to divide the influencing factors of carbon emissions mainly into three categories: population, affluence and technology, and use these factors to be explanatory variables for SCM models. 
The classification of raw coal in China is relatively fixed. It is generally dominated by bituminous coal, accounting for $75 \%-80 \%$. Although IPCC has not directly provided the carbon emission coefficient of raw coal, the carbon emission coefficient of raw coal can be estimated by the weighted average of the carbon emission coefficient from bituminous coal (80\%) and anthracite (20\%). The basic source for extracting Carbon dioxide emissions $\left(\mathrm{CO}_{2}\right)$ data, expressed in ten thousand ton of standard coal, include the statistical yearbooks from provinces and cities in China and the China Energy Statistics Yearbook from 1999 to 2016.

By using Shiyi [38], Talukdar and Meisner [39] method, the energy standard coal coefficient is converted into a measure unit of energy heat in China, and the carbon dioxide emission coefficients of the different energy sources, expressed in $\mathrm{CO}_{2}$ ton per ton of standard coal are: 2.76 for raw coal, 2.145 for crude oil and 1.642 for natural gas.

Population quantity is closely related to the problems of economic development, environmental maintenance, and energy utilization and transportation convenience. Overpopulation growth will bring a lot of negative impacts on the environment. Ratio of the total population to the administrative area, i.e. the population density (POP) is used to denote the density of the local population and is expressed in 10,000 inhabitants per square kilometer.

In Table 1, measures related to the affluence variable are illustrated and selected for the analysis among those more established in the scientific literature.

To discuss the influence factors for carbon emissions, the affluence is one of the important factors that cannot be ignored and in this paper is identified by more than one measures.

Since the $90 \mathrm{~s}$, the influence of the economic growth of a country on the dynamics of environmental pollution has been explained by the concept of the environmental Kuznets curve (EKC). The EKC represents the relationship between quality environmental indicators and income per capita and assumes the shape of an inverted $U$ curve similar to that found by Kuznets [25] in his study on inequality. In EKC analysis the economic factors are usually proxied by the GDP $[4,35]$. The EKC indicates that at the initial level of economic development, with the improvement of life wealth, the environmental pressures increase, as higher income corresponds to a higher level of emissions. Notwithstanding, after a turning point, to further increase income levels, lower emissions are registered, due to the structural changes in the economy and society and greater environmental awareness by population [31], 32. In our study the level of economic development is represented by the growth rate of Gross Domestic Product (GDP) per capita.

Among the affluence measures, the industrial level (INDUSTRIAL) is expressed by the output of the secondary industry to GDP. The secondary industry consumes a lot of energy. For this reason, the output value of the second industry is closely related to carbon emissions.

Trade is also an important source of wealth for a country and so can be included among the affluence variables. Many studies have shown that trade growth has a significant positive effect on carbon emissions [27]. The trade level (TRADE), i.e. rate of the total value of imports and exports to GDP, is used for the aim of this paper. 


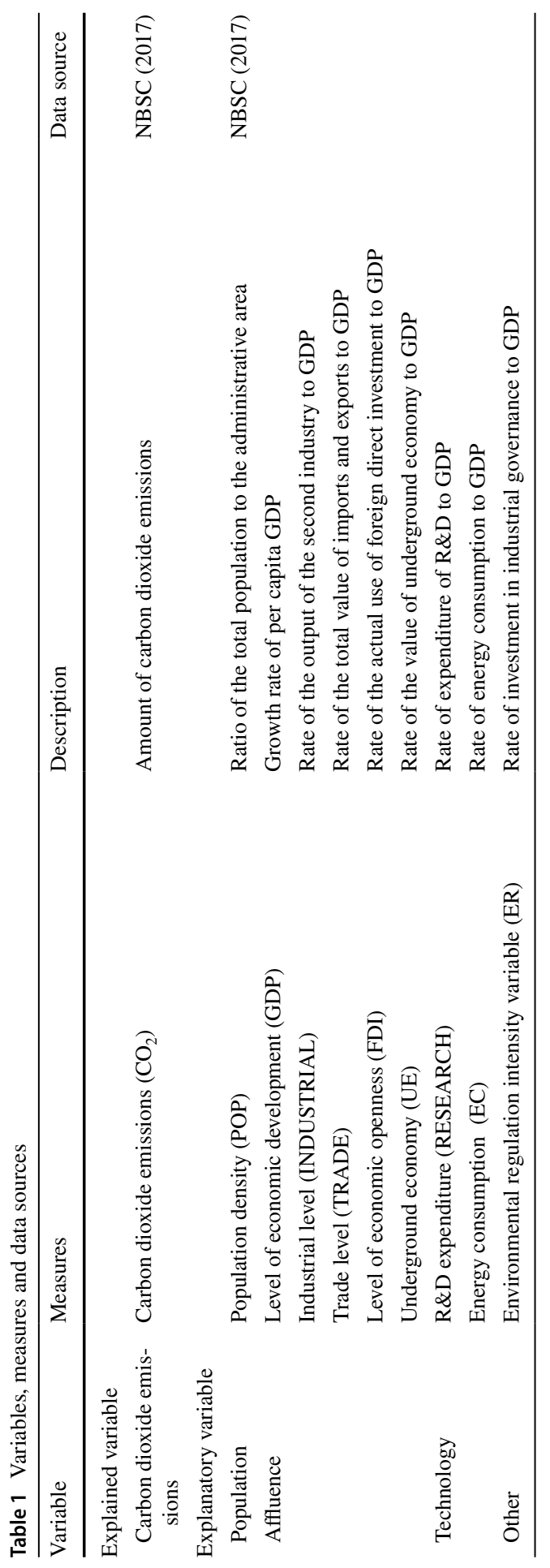


As like the level of trade, the level of economic openness (FDI) is also an important factor affecting the affluence of a country. This study identified the level of economic openness through the rates of the actual use of foreign direct investment to GDP.

Underground economy (UE) is also an influential variable to take into account for the analysis. In line with the established scientific literature [16], 30, 9, 17, which used Multiple Indicators and Multiple Causes approach to calculate the scale of underground economy, the study uses the actual GDP growth rate and the unemployment rate, extracted from the Statistical Yearbook of provinces and municipalities in China, the Yearbook of China's population statistics and the Annals of China's population and employment statistics. Government control, personal disposable income, tax and ratio of self-employment are generally considered as the causes for the spread of this phenomenon. Underground economy has a relatively large scale in China. The results of calculation reveal that the average annual underground economy scale of provinces and municipalities in China is $10.66 \%$, and the scale in certain year register even more than $20 \%$ in some provinces.

A large number of studies have shown that technological progress is an important factor in reducing carbon emissions (Copeland and Taylor 2003), and promoting technological progress has been an effective way to improve energy efficiency. Technology variable is thus fundamental for the purpose of this study and has been proxied by $R \& D$ expenditure (RESEARCH) and Energy consumption (EC) measures. R\&D expenditure can reflect the government's investment in technological progress, to a certain extent, it can reflect technological progress. The rate of R\&D expenditure to GDP is used to represent the variable. Energy consumption represents instead the rate of the amount of energy consumption to GDP. The greater the amount of energy input per unit product, the higher the energy consumption.

Among the other variables which could affect the model, environmental regulation has a self-evident importance for environmental protection and in particular for the carbon emission reductions. The stronger the environmental regulation is, the less environmental pollution will be.

The Environmental regulation intensity variable (ER) is the rate of the investment in industrial governance to GDP. The amount of China's investment in industrial governance reflects the willingness of the government to regulate the environment. Therefore, investment in industrial governance represents the intensity of environmental regulation. Usually, the stricter the environmental regulation is the bigger amount the investment will be.

The sample data selected is including 1999-2016 years. As Chinese National Development and Reform Commission issued the notice which approved six provinces and municipalities to carry out the pilot work of CET system in 2011, this paper selects 1999-2010 period as the pre-intervention years and 2011-2016 period as the postintervention years. 


\section{Analysis of the effect of policy implementation by synthetic control method}

\subsection{SCM method}

In random experiments, once the outputs of the control group and the treatment group are observed, the treatment effect can be calculated. But the difficulty in practice is that, only the outputs of the control group can be observed, and the outputs of the group that does not accept the treatment cannot be observed. The Synthetic Control Method (SCM) elaborated by Abadie and Gardeazabal [1] can be used to overcome this limitation.

In the present study the treatment group is combined by Beijing, Tianjin, Shanghai, Guangdong, Chongqing and Hubei and the control group is made up by other 24 provinces including Hebei, Shanxi, Liaoning, Jilin, Heilongjiang, Jiangsu, Zhejiang, Anhui, Fujian, Jiangxi, Shandong, Henan, Hunan, Hainan, Sichuan, Guizhou, Yunnan, Shaanxi, Gansu, Qinghai, Guangxi, Guangxi, Inner Mongolia, and Ningxia. Since there are six provinces and municipalities to conduct pilot experiments on carbon emissions trading system, these six provinces and municipalities are eliminated from the control group. Due to the lack of data, Tibet is eliminated from the control group too. Hong Kong and Macao instead are not included in this study due to their peculiar political situation. The number of samples is 5940, while the number of samples in the control group is 4554. In order to eliminate the endogenous and autocorrelation effects of variables, endogeneity and autocorrelation are tested on data.

Let $Y_{i t}^{N S}$ be the outcome variable observed for province $i$ at time $t$ with no carbon emission trading system (NS), and $Y_{i t}^{S}$ be the outcome variable with system(S). $Y_{i t}$ indicates the observed actual carbon emissions in province $i, Y_{i t}^{N S}$ represents the hypothetical carbon emissions in province $i$ that are unobservable.

Suppose the general model for the potential outcomes of all the provinces is as represented by the following Eq. (1):

$$
Y_{i t}=Y_{i t}^{N S}+\alpha_{i t} D_{i t}
$$

Here, $i$ stands for province and $t$ stands for the year. For the six pilot provinces and municipalities, if $t \geq 2011$, then $D_{i t}=1, \alpha_{i t}=Y_{i t}-Y_{i t}^{N S} . \alpha_{i t}$ stands for the policy effect.

Several provinces in the control group can be linearly combined to construct as the counterfactual. This counterfactual can be estimated by the linear factor model as indicated in the following Eq. (2):

$$
Y_{i t}^{N S}=\delta_{t}+\theta_{t} Z_{i}+\rho_{t} \mu_{i}+\varepsilon_{i t}
$$

In Eq. (2), $\delta_{t}$ represents a constant time fixed effects which assumes the same value for all provinces $i, Z_{i}$ is the control variable which can be observed in province $i$ with coefficients $\theta_{t} ; \mu_{i}$ is the local fixed effect that cannot be observed and changes over time. $\varepsilon_{i t}$ is a vector of white noise. 
To further estimate the weight of the control group, it is needed to suppose that $X_{1}$ are the $K$ kinds of pre-intervention eigenvectors for the treatment group and $X_{0}$ are the $K$ kinds of pre-intervention eigenvectors for the control group. The weight vector $W^{*}=\left(w_{2}^{*}, \ldots, w_{J+1}^{*}\right)^{\prime}$ is calculated by minimizing the distance function $\left\|X_{1}-X_{0} W\right\|_{V}=\sqrt{\left(X_{1}-X_{0} W\right)^{\prime} V\left(X_{1}-X_{0} W\right)}[2,49]$. In addition, there in the distance function, $w_{j} \geq 0(j=2,3, \ldots, J+1)$ and $w_{2}+w_{3}+\cdots+w_{J+1}=1, V$ is a symmetric positive semi-definite matrix and stands for the relative importance of different feature vector $X$ in structuring weight. The weight of the control group $W^{*}$ depends on $V$, and the latter is selected by Root Mean Square Prediction Error (RMSPE), which enables synthetic control individuals to best approximate the trajectories of individual before policy. Through these calculations, the optimal weights of linear combination are found. These optimal weights are based on the data and avoid the randomness of the researchers' subjective selection of treatment groups.

Before the implementation of carbon emission trading system, the synthetic control provinces can be estimated as:

$$
Y_{i t}=\sum_{j=2}^{J+1} w_{j}^{*} Y_{j t}, t=1999,2000, \ldots, 2010, Z_{1}=\sum_{j=2}^{J+1} w_{j}^{*} Z_{j}
$$

After the implementation of carbon emission trading system, the counterfactual can be estimated as:

$$
\widehat{Y_{i t}}=\sum_{j=2}^{J+1} w_{j}^{*} Y_{i t}^{N S}, t=2011,2012, \ldots, 2016
$$

Then the treatment effect for province $i$ can be calculated by:

$$
\text { Effect }=Y_{i t}-\sum_{j=2}^{J+1} w_{j}^{*} Y_{i t}^{N S}
$$

The basic idea of this SCM model is that several provinces in the control group can be linearly combined to construct more suitable synthetic control provinces. Although each province in the control group is not similar to the province in the treatment group, a synthetic province that is very similar to the real province in the treatment group can be constructed by weighted average. This approach is data driven, the difference between the average outcome of the treatment group and the synthesis control group can estimate the average effect of the policy.

\subsection{Results of the SCM and discussions}

Comparison between predictive measures in real provinces and synthetic provinces is shown in Table 2. It reveals that the synthetic areas are quite similar to the real ones. The difference is relatively large between research and trade, this is firstly because research input and trade between provinces and municipalities 


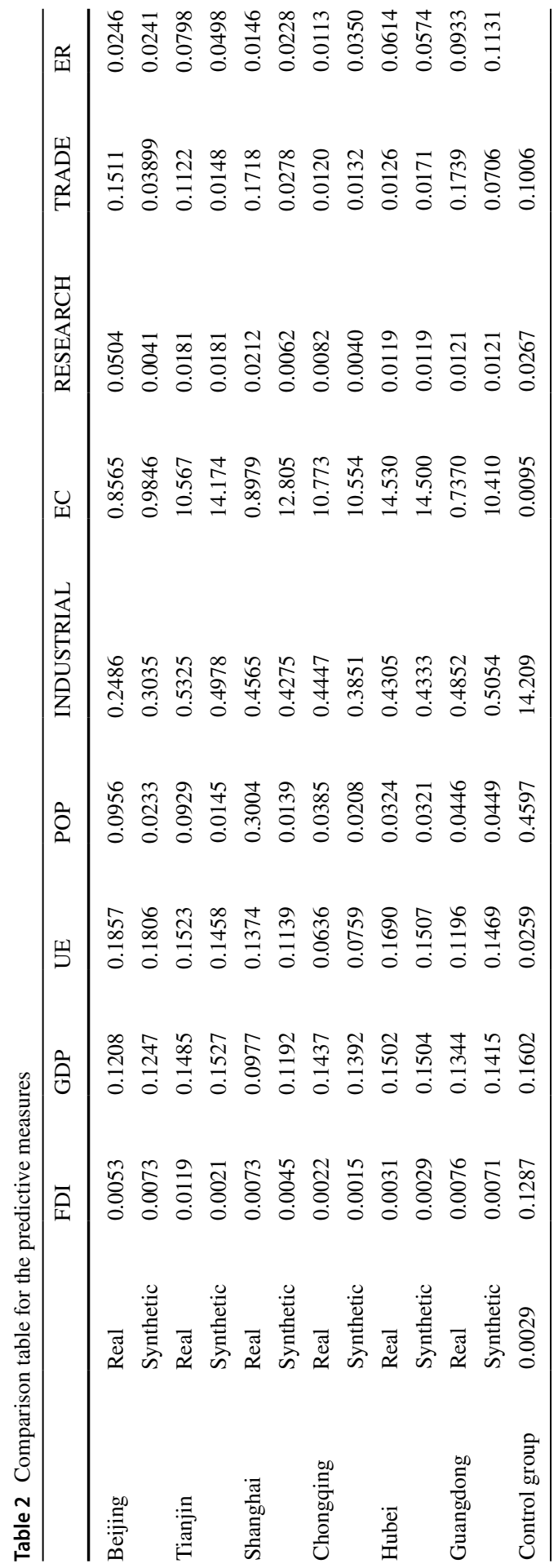


are obviously different from each other, second, in the process of synthesis, the pilot provinces and municipalities are eliminated from the control group. These pilot provinces and municipalities, such as Beijing and Shanghai, tend to have greater similarity in terms of economic development and population density, for this reason their elimination affects the synthetic result. But except for research and trade, other synthetic results such as the level of economic development and underground economy do not register large differences.

The following Table 3 shows the weight of synthetic composition in different provinces and municipalities. In Beijing's carbon dioxide emissions city synthesis, the synthetic provinces consist of 0.794 Hainan, 0.095 Heilongjiang and 0.111 Liaoning. It indicates that situation in Hainan is close to Beijing in terms of $\mathrm{CO}_{2}$ emissions. Chongqing City is hard to simulate due to its peculiarities. Notwithstanding the SCM finds that Guangxi is near to the situations in Chongqing in terms of $\mathrm{CO}_{2}$ emissions.

Based on the comparison between the treatment group and the control group, the carbon emission trading system has a positive effect on carbon emissions for the pilot provinces and municipalities. Figure 2 show carbon dioxide emissions from six pilot areas for carbon emission trading system and their respective synthetic provinces. After the implementation of the carbon emission trading system in 2011, the difference in carbon emissions between the synthetic provinces and the real provinces has been further expanded. Figure 3 illustrates the difference in carbon emissions between the synthetic provinces and the real provinces and its along the analyzed period. It highlights a sharply decreasing trend after the implementation of CET system. The latter has exacerbated the difference especially in Tianjin region, for which the value for the difference reaches 10 in 2011. This circumstance demonstrates a strong positive effect for the implementation of CET system.

In general, discussing Figs. 2 and 3 together, the CET system has a more relevant effect in Beijing, Tianjin, Hubei and Chongqing, where difference gaps have enlarged after 2011. Before the implementation of the CET system, in these provinces, carbon emissions for the real province and the synthetic province assumes similar values, while after the implementation differences increase. Figures 2 and 3 also show that the effect of CET system in Shanghai and Guangdong is not strictly in line with the other pilot provinces due to the province's own development perspective. Although it is not consistent as others', yet a decreasing trend of carbon emissions in the real provinces compared to the synthetic provinces is still presented. Anyway, the results show a better outcome of implementation of CET system, since the latter reduces the carbon emissions to some extent.

Unfortunately, the decreasing trend does not come to be steady and it does not last long. Particularly in Guangdong Province the carbon emissions for the real province and synthetic province assumes similar values in 2016. This is partially due to the fact that CET system has been implemented for about 5 years, but it is still in the experimental stage. The policy may not have been implemented vigorously, and there are other factors which can strongly affect its persistence effect, as discussed in Sect. 5. 


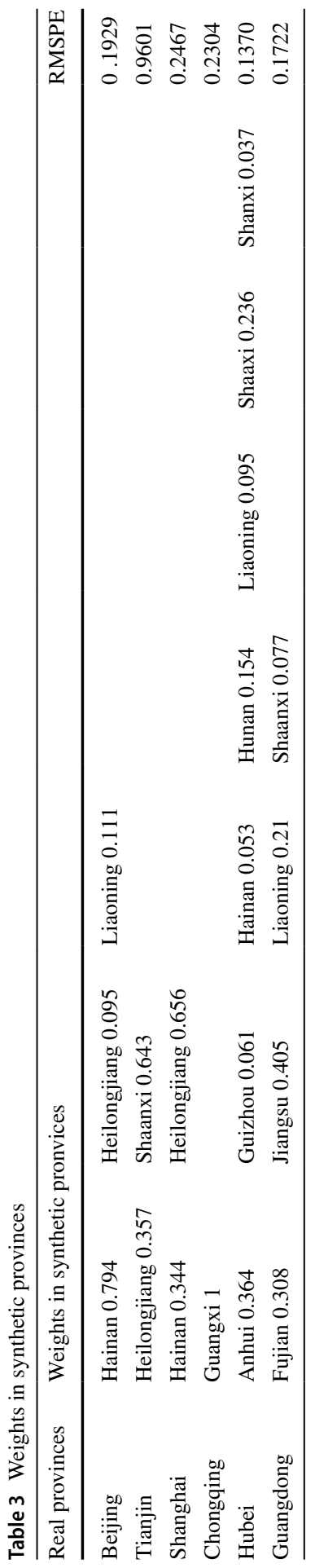




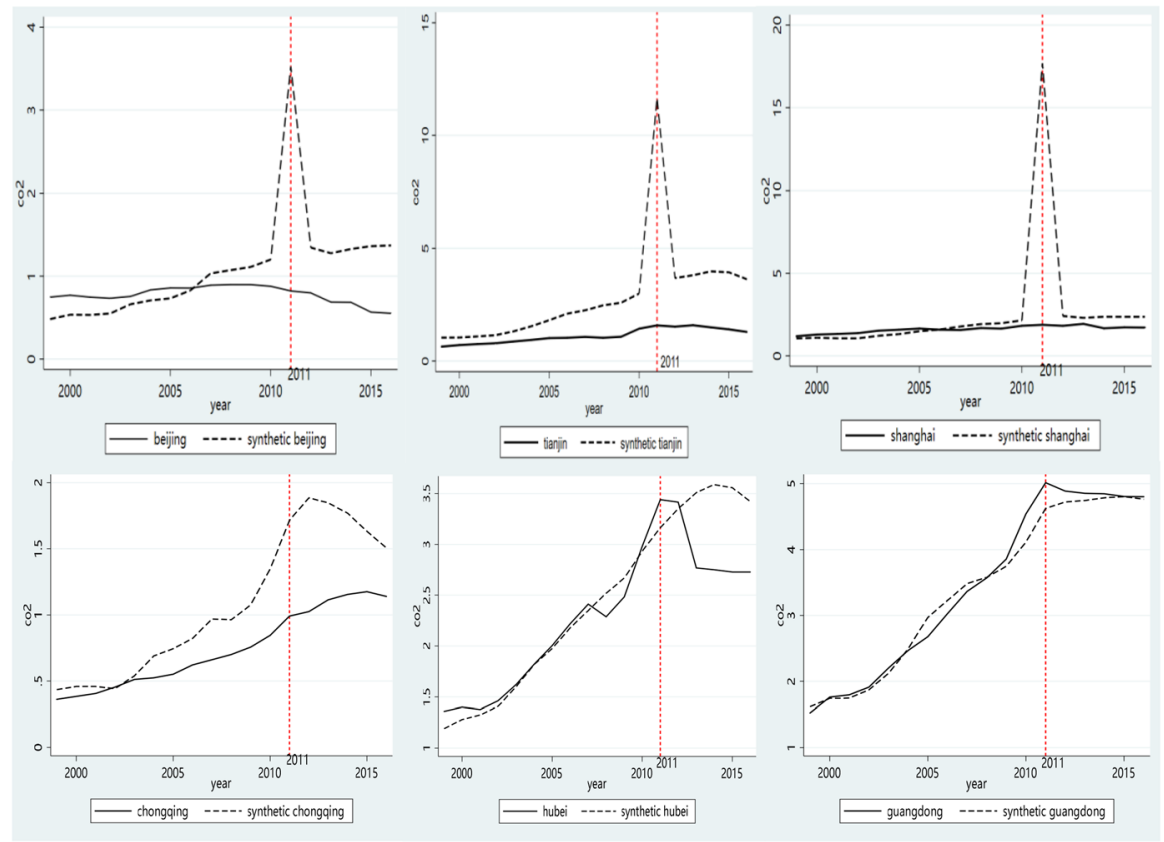

Fig. 2 Carbon dioxide emission of real provinces and synthetic provinces. $\mathrm{CO}_{2}$ emissions on the $\mathrm{y}$-axis are expressed in 10,000 ton of standard coal. Solid lines represent real provinces while dotted lines represent synthetic provinces

\subsection{Placebo test}

Whether the decrease of carbon emissions after the implementation of carbon emission trading policy is a random phenomenon or a nationwide phenomenon can be tested through the placebo test. SCM models usually use placebo test to check the robustness of results $[2,3]$. The test is based on permutation methods. The effect on the CET implementation is estimated separately for each of the provinces in the control group. A permutation distribution can be obtained by iteratively reassigning the treatment to the provinces in the donor pool and estimating "placebo effects" in each iteration. Test every region in the control group and calculate the carbon emissions difference between the real and synthetic provinces. If the difference between the placebo-tested provinces and the other provinces in the control group is significant, the implementation of the carbon emission trading system is effective. All leaveone-out estimates closely track the $\mathrm{CO}_{2}$ emissions series for Chinese provinces before CET implementation in 2011. The resulting estimates for the years after the implementation are all negative and centered around the result produced using the entire donor pool.

Figure 4 reports the results of a leave-one-out re-analysis of the CET implementation, taking from the sample one-at-a-time Bejiing and Shangai provinces that contribute to the synthetic control. The main conclusion of a negative estimate of the CET system implementation on $\mathrm{CO}_{2}$ emissions is robust to the exclusion of any 

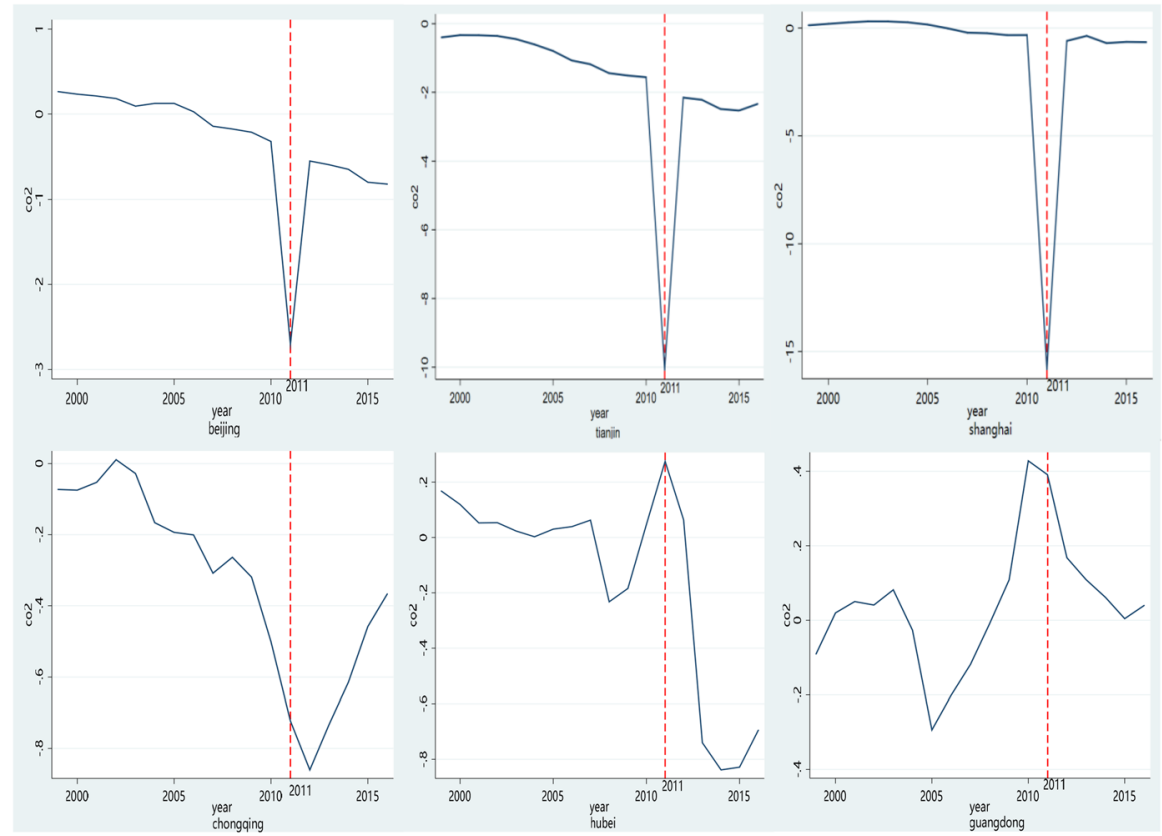

Fig. 3 Trends in carbon dioxide emissions: real provinces $v s$ synthetic provinces. $\mathrm{CO}_{2}$ emissions on the y-axis are expressed in 10,000 ton of standard coal. Solid lines represent the difference between real provinces and synthetic provinces while dotted lines point out the year 2011
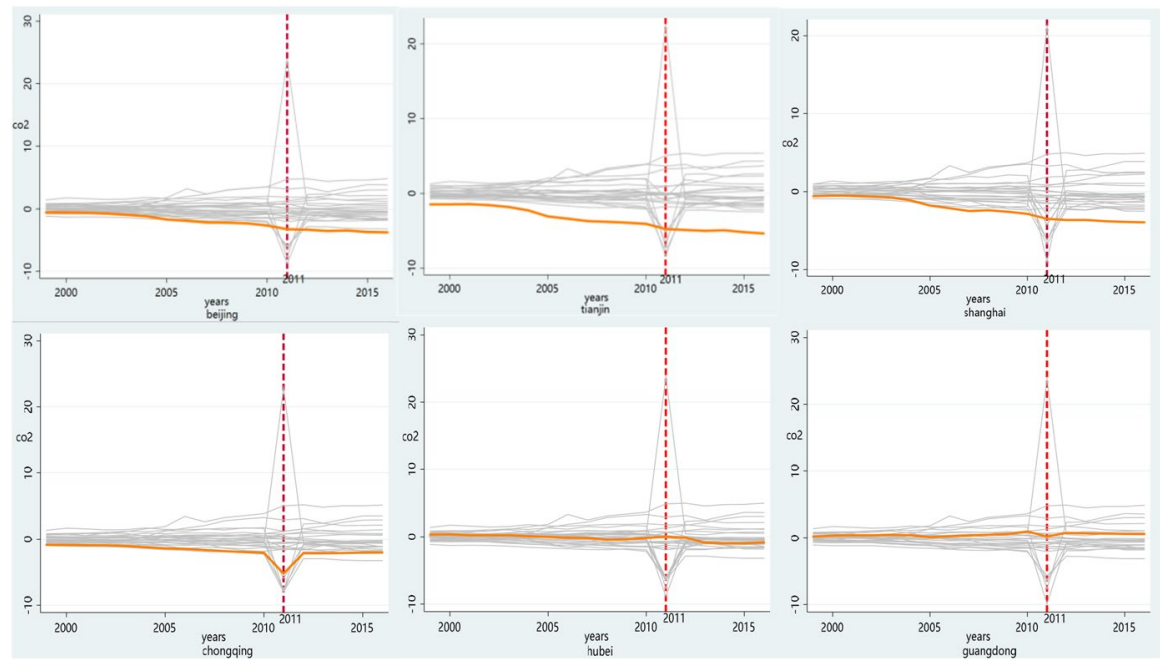

Fig. 4 Placebo test for Beijing and Shanghai. The orange line is a placebo-tested province and dotted lines point out the year 2011 
particular province. As shown in Fig. 4, After the test, the effect of the CET system is still found remarkable. Although the situation in Guangdong is not as good as others, as pointed out in the previous subsection, the carbon emissions goes the same for Guangdong and its synthetic provinces.

The implementation of CET system can really reduce carbon emissions in China. The SCM results show a relevant effect of the implementation of CET system. A significant difference trend is revealed before and after the implementation. This is in line with previous scientific literature [22, 43], which found evidence of the positive effect originated by CET system in China. However, CET system can fully achieve its purpose of reducing the carbon emissions only when the trend tends to be steady [18]. Yet there are many factors affecting this trend and the effect of CET system which have to be in-depth analyzed.

\section{Analysis of causal effect by regression discontinuity}

\subsection{Regression discontinuity model}

The results of Synthetic Control Method show that the implementation of carbon emission trading system has brought a breakpoint effect on carbon emissions. Figure 5 illustrating the polynomial fit of the order one, order two, order three and order four for the six pilot provinces and municipalities, reveals a breakpoint in 2011.

To avoid the direct regression estimation will make the result deviate from the real value, regression discontinuity model is used to identify the causal effect of carbon emission trading system and the causal analysis is used to deduce the persistence of the effect of policy implementation. Regression discontinuity can be used to identify the causal relationship before and after specific events. The premise of its application is to identify which variables have caused breakpoints. In the present study, the relationship between carbon dioxide emissions and other variables is investigated in a narrow time window before and after the implementation of carbon emission trading system by using the following regression discontinuity model:

$$
\operatorname{Ln}\left(C \mathrm{O}_{2}\right)=\mu_{0}+\alpha D_{t}+D_{t} \sum_{i=1}^{k} \beta_{i} t^{i}+\gamma X+{ }_{t}
$$

In Eq. (6), $D_{t}$ is a dummy variable which identify the implementation of the carbon emission trading system. Before the implementation of carbon emission trading system, $D_{t}$ is assumed equal to 0 . After the implementation of carbon emission trading system, $D_{t}$ is instead equal to 1 . $t$ is the treatment variable for the regression discontinuity and measures the length of time for the implementation of carbon emission trading system. It assumes a negative value before the implementation of carbon emission trading system, and a positive value after implementation. $t_{i}$ is a polynomial function for $t$. $X$ is a set of control variables which includes the level of economic development, the level of economic openness, industrial level, trade level and so on. These variables are consistent with the variables used in synthetic control method and all values are in logarithmic specification. In order to check the 

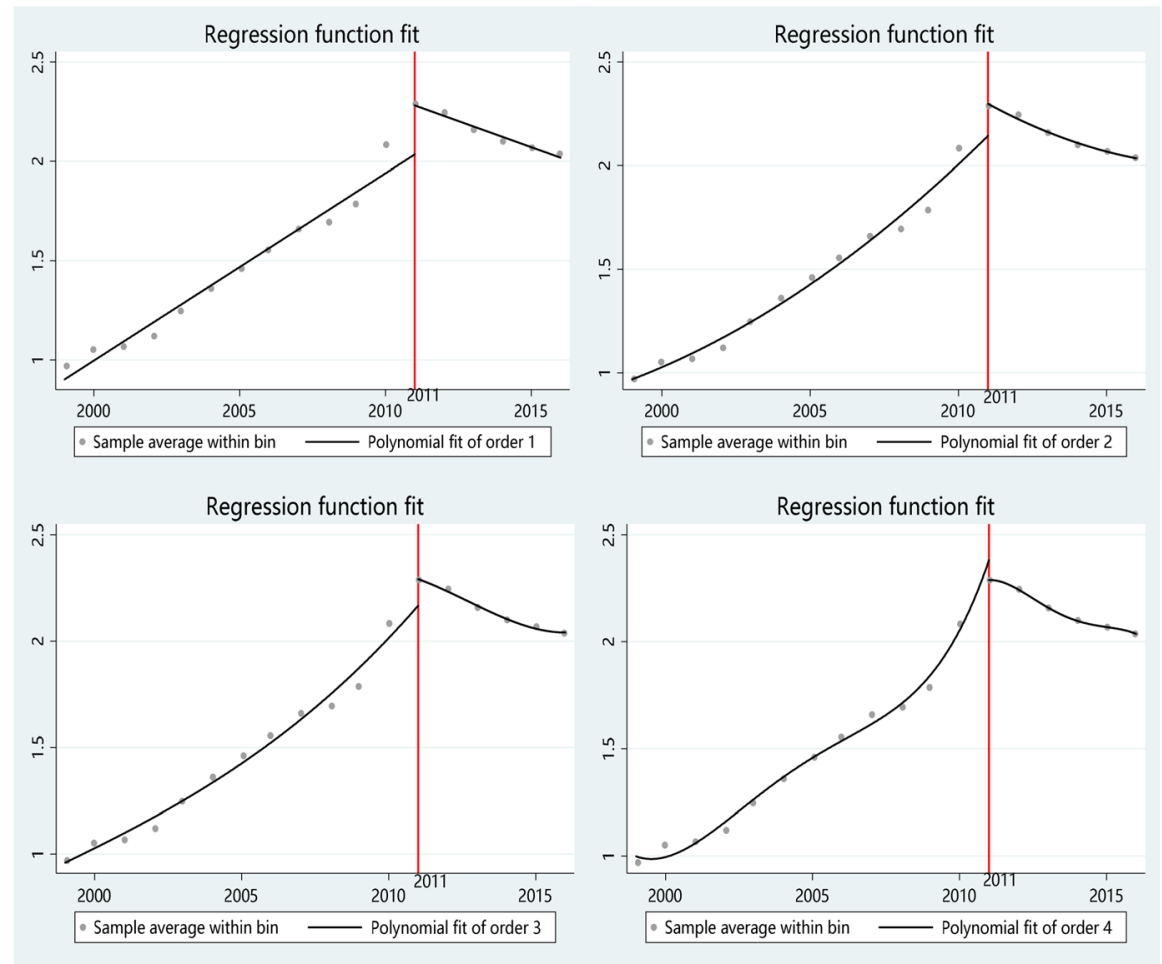

Fig. 5 Regression function fit for order 1 , order 2, order 3 and order 4

robustness of the results of regression discontinuity, this study changes the order of the polynomial and tests the results of the regression at different bandwidth levels, and finds that the results have not changed obviously, thus the results are robust.

\subsection{Results of the RD analysis}

Table 4 shows the results of regression discontinuity and its robust test. The results of the order three and order four processing are omitted because they assumed similar values to those of the first two orders. From the coefficient, the continuous impact of factors on carbon emissions can be easily identified. Here factors influencing the carbon emissions are constructed according to IPAT model, Kaya identity and STIRPAT theory. Causal effects of factors are revealed in Table 4. In general, factors including level of economic development, level of economic openness, research, population density and environmental regulation intensity have positive impact on reducing carbon emissions in China, while underground economy, industrial level, energy consumption and trade level have negative impact on reducing carbon emissions, playing a decisive role in increasing air pollution.

Whether level of economic openness has a positive or a negative impact on carbon emission reduction is still debated by scholars. Some of them believe that 


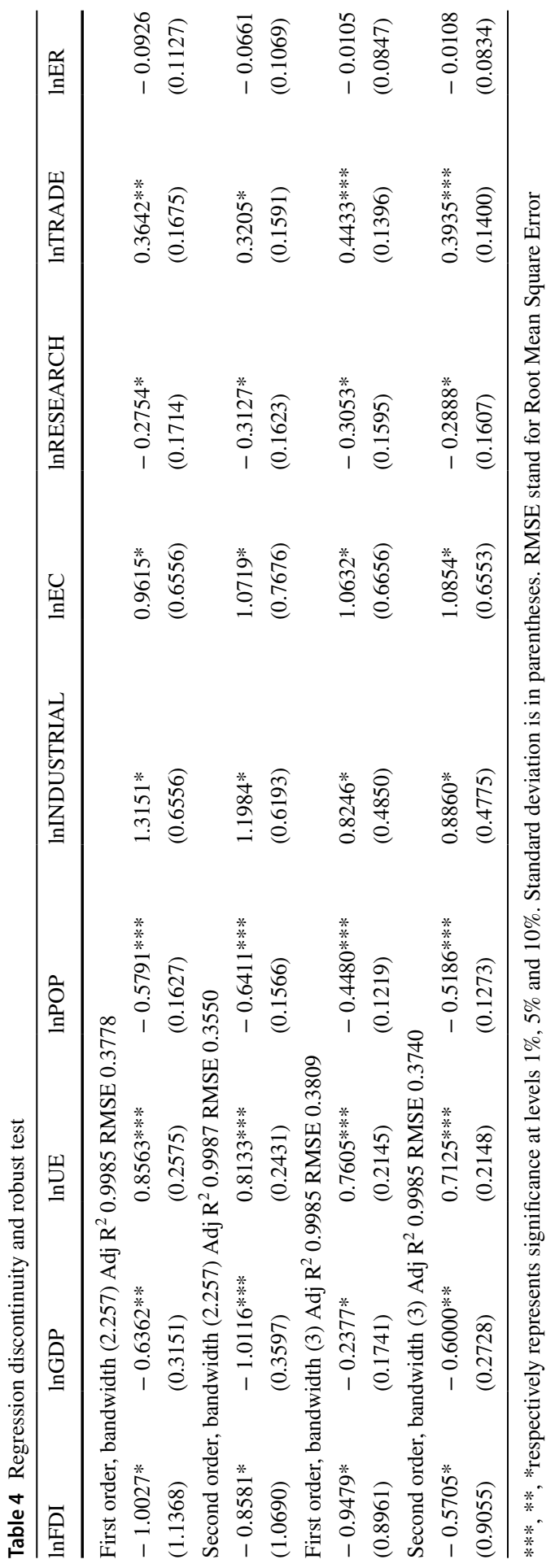


FDI promotes the technology of carbon emissions reduction in the host countries, thereby reducing effectively their carbon emissions [33, 39]. Jorgenson [23] instead found that, in order to attract foreign direct investment, the host countries loosen environmental regulations, generating an increase the carbon emissions. In Table 4, FDI plays a positive role in reducing the carbon emissions. A variation of a percentage unit in FDI can reduce the carbon emissions by almost one percentage unit. This means the technology spillover effect caused by FDI is better absorbed by the six provinces and municipalities in China and has a certain inhibitory effect on carbon emissions.

China's economic growth has gradually transformed into an intensive mode of economic growth. While rising income, demand for durable goods increases, which generally increases carbon emissions. With the improvement of the economic development level, the extensive economy is gradually decreasing, and the consumption of energy is lower. Therefore, the increase of the GDP level has a significant positive impact on carbon emission reduction. Contrary to expectations, population density has a positive impact on reducing carbon emissions. The six provinces and municipalities including Beijing and Tianjin are densely populated and have a high economic development level. So high population density also means a much higher economic development level and more attention paid to the reduction of the carbon emissions.

In addition, governmental research expenditure and regulation also play an important role in reducing carbon emissions. A percentage unit increase of research expenditure can reduce the carbon emissions by almost 0.3 percentage units. Technology progress can effectively reduce the intensity of carbon emissions (Copeland and Taylor, 2003). Thanks to China's development and government intervention policy model also environmental regulation can restrain the increase of carbon emissions. A percentage unit increase of government's environmental regulation intensity can restrain the carbon emissions by almost 0.1 percentage units, demonstrating the role that government regulation plays effectively in reducing carbon emissions.

Instead, the increase in the industrial level, i.e. the output of the secondary industry to GDP and the increase of energy consumption inevitably cause a large increase in carbon emissions. The secondary industry needs more energy consumption than the primary and tertiary industries. The more energy consumes, the more carbon emissions produce.

Trade also is one of the reasons for the carbon emission increase. Exports of high-carbon-intensive products even increase more carbon emissions in China [27]. A percentage unit increase in trade can even cause carbon emissions to increase by about 0.4 percentage units.

It is worth pointing out that the role that underground economy plays in terms of carbon emissions. A percentage unit increase of underground economy increase the carbon emissions by almost 0.8 percentage units, enlightening the importance of the underground economic control. As calculated above, China's underground economy scale is relatively large. Underground economy can avoid governmental regulation increasing carbon emissions.

The coefficients revealed in Table 4 show that the reduction of energy consumption, the upgrading of the industrial structure and the transformation of the economic 
development model have the most relevant influence on the carbon emission reduction. Changing the form of economic development, improving the efficiency of energy use and optimizing the industrial structure are still the most effective policies which could allow the achievement of carbon emission reduction targets in China.

\section{Conclusions and policy suggestions}

China has committed itself to reduce its carbon emissions by $40-45 \%$ over 2005 levels by 2020 and to reach the $20 \%$ rate of renewable energy in primary energy sources by 2030 . Chinese government should strive to promote the implementation of carbon emission trading system to realize these targets.

In this study the integrated approach based on SCM and RD is proposed as a novel framework to conduct policy analyses. In particular the empirical approach is applied to analyze the carbon emission trading system in China, to study the case of six provinces and municipalities, to present the effect of implementation of policy and to investigate the causal factors which ensure the policy persistence effect.

Our findings, in line with the scientific literature in the field [50, 51], indicate that CET system has been effective in China, but there are many factors which could influence its effect henceforth. Results of SCM models analyzed in Sect. 4.2 reveal that CET system play a positive role in reducing the carbon emissions and that China has obtained important outcomes from CET system implementation. Notwithstanding, due to the regional difference, the implementation effect varies in the six provinces and municipalities. Recently, Zhang et al. [50] found that provinces in eastern China have better-matured carbon emission trading market, therefore, witnessed a significant decrease in carbon emission reduction but not in other provinces (middle and western), suggesting a lack of active carbon trading market. For this reason, regional difference should be taken into account when implementing the CET system.

A flexible mechanism has great significance for the establishment and development of CET system, especially during its initial stage [42]. Flexible mechanisms of CET system should be adopted, taking into consideration regional differences, including different economic development models and different carbon dioxide emission intensities. For instance, the use of carbon offsets with different proportionate limits and different safety values, involving ceiling and floor prices, could be recommended as an ideal method.

According to the results discussed in Sect. 5.2, the government should pay attention to the technological effect of FDI, increase the R\&D expenditure related to lowcarbon technology to achieve their own technological innovation and reduce the carbon emissions intensity.

Besides, exports of high-carbon-intensive products aggravate the deterioration of trade structure. By reducing the proportion of high-carbon emissions exports and increasing the proportion of low-carbon emissions exports, stable export growth can be adequately maintained without increasing carbon emissions. At the same time, the government needs to upgrade the export product structure through policy guidance and to promote the transformation of trade model to environment friendly.

In addition, the government should strive enterprises to meet resource-conserving and environment-friendly targets. In order to achieve sustainable economic and social 
development, the industrial substrate needs to accept the challenge of turning from coal-based energy sources to an environment-friendly one. Shen and Peng [36] found that the industrial agglomeration exerted an apparent spatial spillover effect due to the effects of external economies of scale and scope, but the deterioration of environmental quality was not an inevitable outcome of the agglomeration of industry.

The government should promote clean production, gradually change the coalbased high-consumption and high-pollution energy consumption structure, reduce the energy intensity and optimize the energy structure, and promote the substantial transformation of economic growth mode. Since the Chinese transport sector is characterized by high energy consumption, implementing reasonable pathways to reduce energy intensity of different provinces' transport sectors are of great significance for the sustainable development in China [45]. Most of the existing regional emission reduction policies are decomposed from the state to the provinces, cities and counties. However, the objective existence of inter-regional economic links determines that more attention should be paid to inter-regional horizontal joint emission reduction, in order to avoid carbon leakage caused by the break of production chain. Policy modeling and implementation cannot ignore local conditions and contextual variables. Because of the differences in economic, geographical, technological and environmental conditions in various areas [37], each provincial government should formulate a targeted policy according to local conditions, ensuring an economic and environmentally sustainable growth in the future.

Investigating the carbon emission outcomes at a provincial level, on one hand strengthens the findings from previous studies, but on the other hand, lacks detailed information on the sources of carbon emission reduction by sectors and industries. This originates the need for further research efforts aiming to examine the share of carbon emission reduction by different sectors and to identify the most responsive sectors to the carbon emission trading systems.

Acknowledgments Pierluigi Toma received Research support from the Italian Ministry of University, Project PON Attraction and International Mobility, n. AIM1823220.

Funding Open access funding provided by Università del Salento within the CRUI-CARE Agreement.

Open Access This article is licensed under a Creative Commons Attribution 4.0 International License, which permits use, sharing, adaptation, distribution and reproduction in any medium or format, as long as you give appropriate credit to the original author(s) and the source, provide a link to the Creative Commons licence, and indicate if changes were made. The images or other third party material in this article are included in the article's Creative Commons licence, unless indicated otherwise in a credit line to the material. If material is not included in the article's Creative Commons licence and your intended use is not permitted by statutory regulation or exceeds the permitted use, you will need to obtain permission directly from the copyright holder. To view a copy of this licence, visit http://creativecommons.org/licen ses/by/4.0/.

\section{References}

1. Abadie, A., Gardeazabal, J.: The economic costs of conflict: a case study of the Basque Country. Am. Econ. Rev. 93(1), 113-132 (2003) 
2. Abadie, A., Diamond, A., Hainmueller, J.: Synthetic control methods for comparative case studies: estimating the effect of California's tobacco control program. J. Am. Stat. Assoc. 105(490), 493-505 (2010)

3. Abadie, A., Diamond, A., Hainmueller, J.: Comparative politics and the synthetic control method. Am. J. Political Sci. 59(2), 495-510 (2015)

4. Agras, J., Chapman, D.: A dynamic approach to the environmental Kuznets curve hypothesis. Ecol. Econ. 28(2), 267-277 (1999)

5. Bai, J., \& Ng, S. (2019). Matrix completion, counterfactuals, and factor analysis of missing data, arXiv preprint, 1910.06677.

6. Böhringer, C., Dijkstra, B., Rosendahl, K.E.: Sectoral and regional expansion of emissions trading. Resource Energy Econ. 37, 201-225 (2014)

7. Burniaux, J. M., Martin, J. P., Nicoletti, G., \& Martins, J. O. (1992). GREEN a Multi-Sector, MultiRegion General Equilibrium Model for Quantifying the Costs of Curbing $\mathrm{CO}_{2}$ Emissions.

8. Brodersen, K.H., Gallusser, F., Koehler, J., Remy, N., Scott, S.L.: Inferring causal impact using Bayesian structural time-series models. Ann. Appl. Stat. 9(1), 247-274 (2015)

9. Cassar, A.: An index of the underground economy in Malta. Bank Valletta Rev. 23(2), 44-62 (2001)

10. Chen, Y.T.: A distributional synthetic control method for policy evaluation. J. Appl. Economet. 35(5), 505-525 (2020)

11. Cong, R., Lo, A.Y.: Emission trading and carbon market performance in Shenzhen China. Appl. Energy 193, 414-425 (2017)

12. Crocker, T.D.: The structuring of atmospheric pollution control systems. Econ. Air Pollution 29(2), 288 (1966)

13. Cui, L.B., Fan, Y., Zhu, L., Bi, Q.H.: How will the emissions trading scheme save cost for achieving China's 2020 carbon intensity reduction target? Appl. Energy 136, 1043-1052 (2014)

14. De Leo, F., Miglietta, P.P.: The contribution of environmental indicators to the sustainable performance of countries. Int. J. Sustain. Policy Practice 11, 12-26 (2015)

15. Ehrlich, P.R., Holden, J.P.: Impact of population growth. Science 171(3), 1212-1217 (1971)

16. Frey, B.S., Weck, H.: Estimating the shadow economy: a "naïve" approach. Oxf. Econ. Pap. 35(1), 23-44 (1983)

17. Giles, D.E., Tedds, L.M., Werkneh, G.: The Canadian underground and measured economies: granger causality results. Appl. Econ. 34(18), 2347-2352 (2002)

18. Fang, G., Tian, L., Liu, M., Fu, M., Sun, M.: How to optimize the development of carbon trading in China-enlightenment from evolution rules of the EU carbon price. Appl. Energy 211, 1039-1049 (2018)

19. Gobillon, L., Magnac, T.: Regional policy evaluation: interactive fixed effects and synthetic controls. Rev. Econ. Stat. 98(3), 535-551 (2016)

20. Hahn, J., Todd, P., Van der Klaauw, W.: Identification and estimation of treatment effects with a regression-discontinuity design. Econometrica 69(1), 201-209 (2001)

21. Huang, P., Zhou, J.: The existing problems and solutions of China's carbon markets from international market practice. LanZhouXueKan 10, 140-147 (2014)

22. Hübler, M.: Technology diffusion under contraction and convergence: a CGE analysis of China. Energy Econ. 33(1), 131-142 (2011)

23. Jorgenson, A.K.: Does foreign investment harm the air we breathe and the water we drink? A crossnational study of carbon dioxide emissions and organic water pollution in less-developed countries, 1975 to 2000. Organ. Environ. 20(2), 137-156 (2007)

24. Kaya, Y. (1989). Impact of carbon dioxide emission control on GNP growth: interpretation of proposed scenarios. Intergovernmental Panel on Climate Change/Response Strategies Working Group, May.

25. Kuznets, S.: Economic growth and income inequality. Am. Econ. Rev. 45(1), 1-28 (1955)

26. Lee, D.S.: Randomized experiments from non-random selection in US House elections. J. Econ. 142(2), 675-697 (2008)

27. Lin, B., Sun, C.: Evaluating carbon dioxide emissions in international trade of China. Energy Policy 38(1), 613-621 (2010)

28. Liu, L., Chen, C., Zhao, Y., Zhao, E.: China' s carbon-emissions trading: Overview, challenges and future. Renew. Sustain. Energy Rev. 49, 254-266 (2015)

29. Lo, A.Y.: Carbon trading in a socialist market economy: can China make a difference? Ecol. Econ. 87, 72-74 (2013) 
30. Loayza, N. (1999). The economics of the informal sector: a simple model and some empirical evidence from Latin America. The World Bank.

31. Miglietta, P.P., De Leo, F., Toma, P.: Environmental Kuznets curve and the water footprint: an empirical analysis. Water Environ. J. 31(1), 20-30 (2017)

32. Pal, D., Mitra, S.K.: The environmental Kuznets curve for carbon dioxide in India and China: growth and pollution at crossroad. J. Policy Modeling 39(2), 371-385 (2017)

33. Perkins, R., Neumayer, E.: Do recipient country characteristics affect international spillovers of $\mathrm{CO}_{2}$-efficiency via trade and foreign direct investment? Clim. Change 112(2), 469-491 (2012)

34. Samartsidis, P., Seaman, S.R., Presanis, A.M., Hickman, M., De Angelis, D.: Assessing the causal effect of binary interventions from observational panel data with few treated units. Stat. Sci. 34(3), 486-503 (2019)

35. Selden, T.M., Song, D.: Environmental quality and development: is there a Kuznets curve for air pollution emissions? J. Environ. Econ. Manag. 27(2), 147-162 (1994)

36. Shen, N., \& Peng, H. (2020). Can industrial agglomeration achieve the emission-reduction effect?, Socio-Economic Planning Sciences, 100867.

37. Shi, Z., She, Z., Chiu, Y. H., Qin, S., \& Zhang, L. (2020). Assessment and improvement analysis of economic production, water pollution, and sewage treatment efficiency in China, Socio-Economic Planning Sciences, 100956.

38. Shiyi, C.: Energy consumption, $\mathrm{CO}_{2}$ emission and sustainable development in chinese industry. Econ. Res. J. 4, 1-5 (2009)

39. Talukdar, D., Meisner, C.M.: Does the private sector help or hurt the environment? Evidence from carbon dioxide pollution in developing countries. World Dev. 29(5), 827-840 (2001)

40. Castillo, V., Garone, L.F., Maffioli, A., Salazar, L.: The causal effects of regional industrial policies on employment: a synthetic control approach. Reg. Sci. Urban Econ. 67, 25-41 (2017)

41. Viviano, D., \& Bradic, J. (2019). Synthetic learner: model-free inference on treatments over time, arXiv preprint, 1904.01490.

42. Wang, Z., Wang, C.: How carbon offsetting scheme impacts the duopoly output in production and abatement: analysis in the context of carbon cap-and-trade. J. Clean. Prod. 103, 715-723 (2015)

43. Weitzel, M., Hübler, M., Peterson, S.: Fair, optimal or detrimental? Environmental vs. strategic use of border carbon adjustment. Energy Econ. 34, S198-S207 (2012)

44. Xu, Y.: Generalized synthetic control method: causal inference with interactive fixed effects models. Polit. Anal. 25(1), 57-76 (2017)

45. Zha, J., Tan, T., Fan, R., Xu, H., Ma, S.: How to reduce energy intensity to achieve sustainable development of China's transport sector? A cross-regional comparison analysis. Socioecon. Plann. Sci. 71, 100772 (2020)

46. Zhang, Z.: China in the transition to a low-carbon economy. Energy Policy 38(11), 6638-6653 (2010)

47. Zhang, Z.: Crossing the river by feeling the stones: the case of carbon trading in China. Environ. Econ. Policy Stud. 17(2), 263-297 (2015)

48. Zhang, D., Karplus, V.J., Cassisa, C., Zhang, X.: Emissions trading in China: progress and prospects. Energy Policy 75, 9-16 (2014)

49. Zhang, J., Zhong, C., Yi, M.: Did Olympic Games improve air quality in Beijing? Based on the synthetic control method. Environ. Econ. Policy Stud. 18(1), 21-39 (2016)

50. Zhang, W., Li, J., Li, G., Guo, S.: Emission reduction effect and carbon market efficiency of carbon emissions trading policy in China. Energy 196, 117117 (2020)

51. Zhang, Y., Li, S., Luo, T., Gao, J.: The effect of emission trading policy on carbon emission reduction: evidence from an integrated study of pilot regions in China. J. Clean. Prod. 265, 121843 (2020)

52. Zhao, X., Wu, L., Li, A.: Research on the efficiency of carbon trading market in China. Renew. Sustain. Energy Rev. 79, 1-8 (2017)

53. Zhou, W., Chen, Y.: On the status quo, problems and countermeasures of China's carbon trading market. J. Jiangxi University Finance Econ. 3, 12-17 (2011)

54. Zhou, P., Zhang, L., Zhou, D.Q., Xia, W.J.: Modeling economic performance of interprovincial $\mathrm{CO}_{2}$ emission reduction quota trading in China. Appl. Energy 112, 1518-1528 (2013)

Publisher's Note Springer Nature remains neutral with regard to jurisdictional claims in published maps and institutional affiliations. 